\title{
ENVIRONMENTAL EDUCATION OF AN ARCHITECT: THE CASE OF FINAL-YEAR DESIGN STUDIO AT THE TECHNION, ISRAEL \\ DOI: http://dx.doi.org/10.26687/archnet-ijar.v12i1.1305
}

\author{
Jonathan Natanian*, Or Aleksandrowicz
}

\section{Keywords}

environmental design education; integrated environmental design; environmental design studio; sustainable design language; performance-based design; design research; architectural education.

ArchNet-IJAR is indexed and listed in several databases, including:

- Avery Index to Architectural Periodicals

- EBSCO-Current Abstracts-Art and Architecture

- CNKI: China National Knowledge Infrastructure

- DOAJ: Directory of Open Access Journals

- Pro-Quest

- Scopus-Elsevier

- Web of Science

\begin{abstract}
The need to integrate environmental design into the education of architects has been widely recognized in recent years, leading to the development of different pedagogical approaches. While most studies on this challenge are dedicated to the theoretical aspects of creating new pedagogical frameworks, only few examine their implementation in actual student design projects. This paper reports on the integration of environmental concepts in finalyear undergraduate student projects at the Faculty of Architecture and Town Planning at the Technion - Israel Institute of Technology. The design studio followed an iterative approach to the integration of environmental knowledge in design, which meant that the design process progressed through a continuous dialogue between environmental data production and other design considerations. The application of the iterative approach is examined in this paper through four student projects from two consecutive years of teaching, with each case focusing on different stage of the design process. The outcomes of the design studio indicate that the iterative approach has a potential to make environmental design a defining theme in final-year design projects, especially when applied consciously and at well-defined design stages. In addition, the use of quantitative indicators and analytic tools was found to invigorate innovative environmental design strategies. However, preliminary training and theoretical background in environmental design were found to be critical to the students' ability to integrate their body of knowledge effectively and holistically. Based on these outcomes, this paper offers guidelines for future development of environmentally-driven design studios.
\end{abstract}

\footnotetext{
J. Natanian", O. Aleksandrowicz

J. Natanian*, PhD candidate, Chair of Building Technology and Climate Responsive Design, Technical University of Munich, Arcisstr. 21, Munich D-80333, Germany.

O. Aleksandrowicz, Adjunct Senior Lecturer, Faculty of Architecture and Town Planning, Technion - Israel Institute of Technology, Haifa, Israel.
} 


\section{INTRODUCTION}

The environmental impact of buildings and urban areas has been attracting, for more than two decades now, growing interest from researchers and practitioners, followed by a wide acknowledgement of the need for integrating environmental sensitivities into architectural education and training (Hassanpour et al., 2017; Ismail et al., 2017). Such a need calls for a revision of architectural curricula in a way that will enable architecture students to master the core concepts and tools of building science and to base design decisions on scientific knowledge. However, despite these emerging trends, it can be argued that the products of scientific research on building performance and bioclimatic design still has a limited effect on common architectural design practices (Yannas, 2013), as well as on the way architecture is taught (Altomonte, 2009).

In recent years, sustainable design has been integrated into academic programs in several institutions around the world (Ismail et al., 2017), with the design studio, as a core element of architectural education, becoming a focal point for such an integration (Salama, 2008; Khalid, 2012). Some notable examples include the Comprehensive Environmental Design (CED) approach at the Dawood College of Engineering and Technology in Karachi, which focuses on the analysis of the micro-urban context as a basis for students' design proposals (Ahmed, 2010); the environmental "Future Cities" studio at the University of Arizona (Susannah, 2013), which adopts a more holistic approach and bridges between the building and the urban scales; and the "gamification" approach applied at MIT, in which students learn how to integrate energy simulation in their design process through a 90-minute hands-on energy simulation "game" (Reinhart et al., 2012). Gamification was also used to promote environmental design at Philadelphia University in the "Survivor Studio", an experimental challenge attempted to actively engage students with sustainability, among other non-design studio curriculum (Rob, 2002).

Recently, a three-year, multi-national European project entitled EDUCATE (Environmental Design in University Curricula and Architectural Training in Europe) produced a conceptual framework that would support the creation of comprehensive environmentally-aware academic programs in the field of architecture (Altomonte et al., 2012; Altomonte et al., 2014). The work introduced five different pedagogical models for the integration of sustainable design into architecture school curricula (Figure 1): Parallel, where environmental design is taught separately from other design approaches; Partially Integrated, where environmental design is partially integrated into other design fields; Fully Integrated, where various disciplines converge around the central core of the design studio project; Iterative, where knowledge is progressively deepened through a series of cognitive "loops" or iterations; and Elective, where optional courses in environmental design are offered to students. The differentiation in pedagogical approaches was meant to conform to a variety of teaching cultures and organizations. These models partially correlate with the three approaches of integrating sustainable design into architectural curriculum suggested already by Wright (2003): preservation of the existing educational framework; selective integration; and a full revision of the whole curriculum to include sustainable design aspects.

This paper examines the effects of implementing the iterative model in an architectural finalyear design studio. According to Altomonte (2014), the iterative model is unique in the way it is based on continuous interdependencies between different domains of knowledge. Design develops through a gradual process of increasing complexity in both the technical and theoretical environmental contents of the course, relating them in every stage to other design considerations. Such a process has many similarities with a real-life design process that 
continuously integrates environmental knowledge, and is therefore highly suitable for a finalyear design projects.

The paper consists of two parts: the first section provides a brief overview of the pedagogical structure of the course and its iterative framework, while its main part elaborates on the way the iterative model was implemented during the course of the architectural design studio. The integration of the environmental approach into architectural design is exemplified through four individual student projects, each focuses on a different stage of the design process. The paper concludes with a discussion of the prospects of integrating environmental knowledge into architectural education, highlighting findings regarding the iterative approach, and offering guidelines for future evolution of environmental design studios.

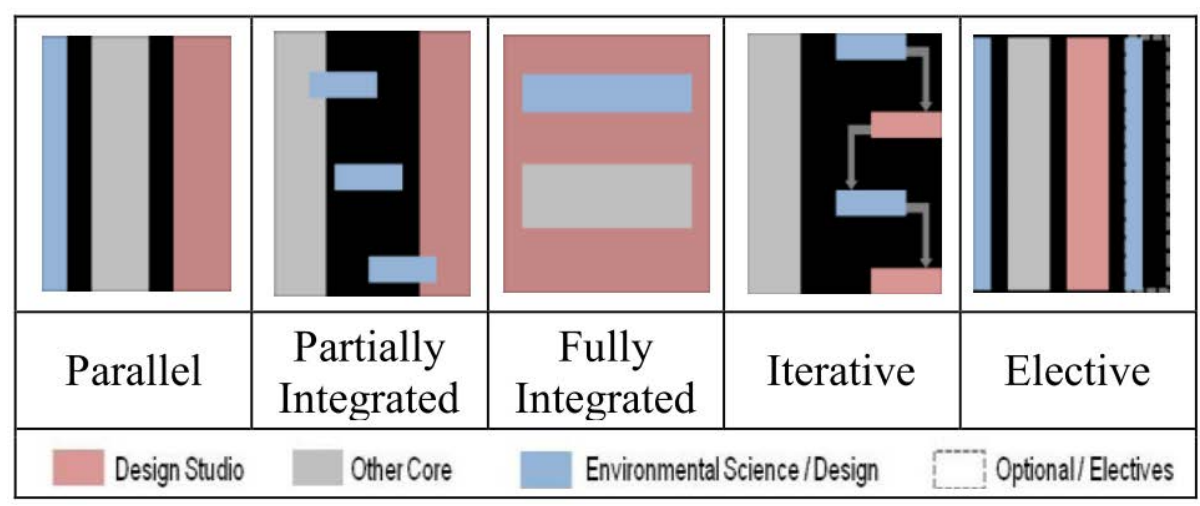

Figure 1: Five models of integration of environmental studies into architectural school curricula (Source: Altomonte et al., 2012).

\section{COURSE STRUCTURE AND CONTENTS}

In 2014, the Architecture Program at the Faculty of Architecture and Town Planning at the Technion (Israel Institute of Technology) was restructured from a five-year to a six-year curriculum to include specialization in five major themes: environmental design, history and theory, preservation, urban design, and digital architecture. During the first three years of study, the basic concepts of environmental design are being taught in mandatory courses (reflecting Altomonte's "Partially Integrated" model). In years 4-6, vertical studio courses in environmental design are offered parallel to the other four, "non-environmental" specialized themes, supported by theoretical and performance-based courses (reflecting Altomonte's "Elective" learning process).

In the final-year studio at the Technion, students are divided into five groups; each follows one of the curriculum's five themes of specialization, including environmental design. Teaching in all groups follows the emerging concept of "design research" (Kulper, 2013), which means that students are expected to define a theoretical framework and methodology for their work and to formulate design decisions based on evidence extracted by theoretical research. Reflecting Altomonte's "iterative" process, the research-based design approach encourages students to constantly shift between the theoretical and the design-specific domains, informing their design decisions with context-specific and theoretical insights. The final-year environmental design studio, entitled "Articulation, Space, and Sustainability", adopted a similar approach and focused on the integration of environmental performance concepts into creative architectural design process. 
As the concept of research-based design suggests, the environmental design studio synthesized scientific knowledge and formal design work. Arch. Shmaya Serfaty, a partner in one of Israel's leading architectural firms, acted as the studio's design director, while the first author provided the theoretical framework for environmental design and focused on environmental research methodologies. The iterative approach was regarded as a natural choice for the design process at the studio, since it was built upon the interdependency between the research course and the design studio. In order to ensure the integration of both domains of knowledge, both tutors attended each personal studio tutorial. Additionally, the studio tutorials were supplemented with a research course, led by the first author, whose aim was to provide support for the research aspects of the project, including introduction to the relevant body of theoretical knowledge, guidance in implementing performance-based analytical tools, and assistance in writing the project's thesis.

\section{CASE STUDY: FINAL-YEAR STUDENTS' PROJECTS}

The integration of environmental research into the "Articulation, Space, and Sustainability" studio followed the main milestones of the Technion's final-year project. The design process began with the selection of a research theme and a specific physical site by each student. An individual research was then conducted on the broader context of each theme, which brought forward social, geo-political, and historical issues of the local context. These aspects were complimented by a climatic analysis specific to the project's site. Based on the research findings and the climatic analysis, the design process followed a structured path, consisting of four design stages: conceptual design, on-site massing, programmatic layout, and detailed building design. The following sections provide examples for each of the design stages through exemplary student projects from two consecutive years of teaching the course. Altogether, the projects demonstrate the process of implementing an iterative environmental design approach from the project outset to the design outcome.

\section{Conceptual design}

The student Maayan Sheiman focused on the urban regeneration of the IMI (Israel Military Industries) compound in Tel Aviv (Figures 2,3). The acute soil pollution of this $44,000 \mathrm{~m}^{2}$ site, caused by years of industrial military activity, prevented its development for decades despite its central location. At the project outset, Sheiman conducted a comprehensive review on the site's current state of pollution and soil remediation practices and technologies as part of the environmental research course. The project's rationale was based on this review, leading to a responsive design strategy which had been developed in the design studio for the site's responsive regeneration.

The design strategy outlined an innovative process in which soil treatment is performed simultaneously with gradual reconstruction of the site. Quantitative assessment of the different degrees of soil pollution within the site was used during the conceptual design process to form an "inverse topography" that reflected the quantification of pollution percolation into the ground. Inspired by its historical purpose, the entire site was then designed to be transformed into a soil purification factory, one which will also reconnect to its surrounding urban fabric. Based on this starting point, an iterative process was formulated shifting between the quantitative scientific remediation strategy and the qualitative aspects of architectural design. This case exemplifies the potential of a research-based environmental 
concept to help ignite the design process in the studio, as well as to serve as the backbone for the design process in its following stages.

Soil pollution topography mapping

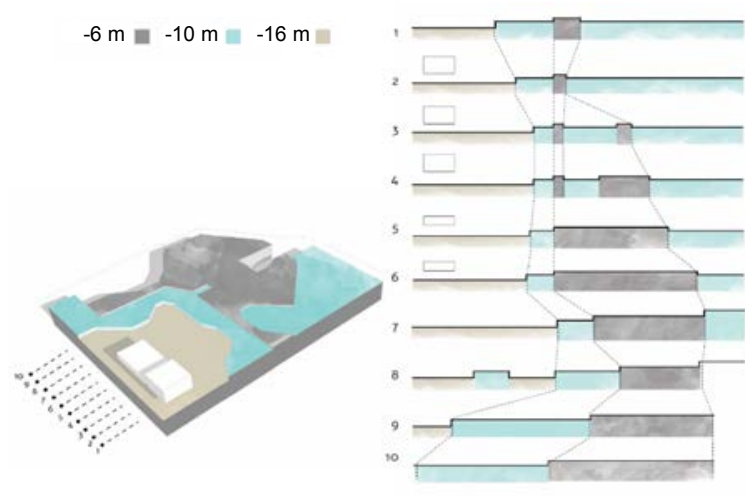

Soil remediation research

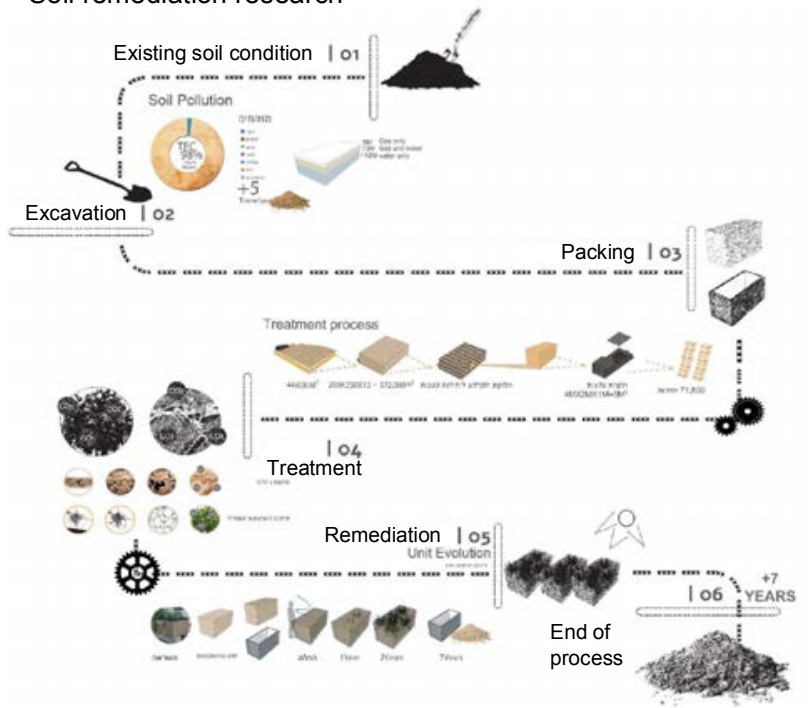

Figure 2: Generative design scheme driven by a soil remediation process in a contaminated former military industrial zone in Tel Aviv (project by Maayan Sheiman, 2016).

Design concept based on remediation scheme and time line

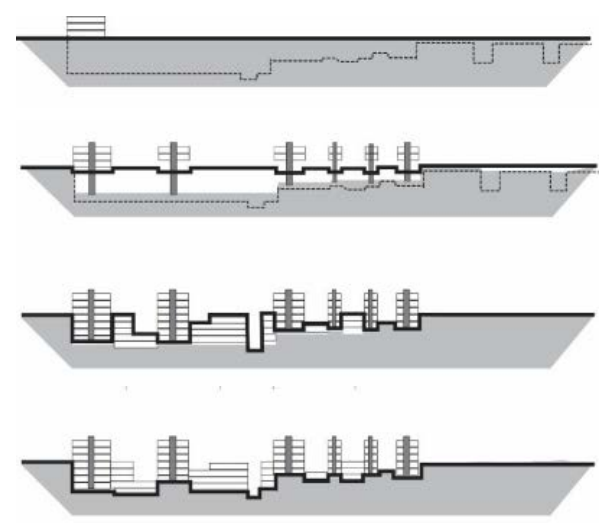

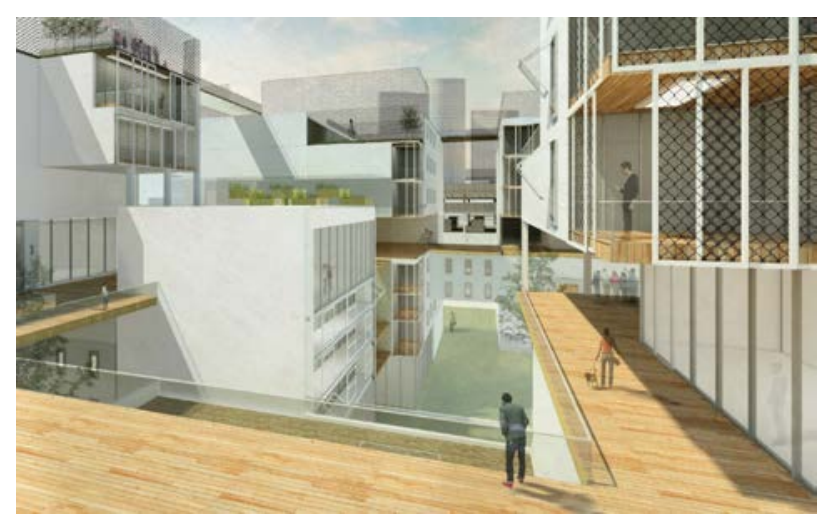

Figure 3: Generative design scheme driven by a soil remediation process in a contaminated former military industrial zone in Tel Aviv (project by Maayan Sheiman, 2016).

\section{Massing}

The concept of urban compactness in Jerusalem, Israel's capital city, had served as one of the key drivers in Nattalie Mor's project (Figure 4). The constitutional role of the city has left its impact on its urban form, creating a large inner-city segregated compound consisting of the Knesset (the Israeli parliament) among other government office buildings. The project is based on the concept of relocating the Israeli parliament to the Clal Building, one of Jerusalem's "white elephants" situated in its city centre. The concept was given form by a programmatic deconstruction of the existing parliament to its different functional roles and 
their re-composition according to a new spatial hierarchy, in which the city and its citizens interact democratically beneath, above, and around the new built volumes.

For the new massing of the building, Mor applied methods and analytic tools taught during the supplementary research module. As part of the first module's assignments, a detailed climatic analysis was conducted, which in this case highlighted the importance of solar radiation availability during winter and mid-season to both indoor and outdoor spaces. These findings were applied in the design studio to position the new masses following radiation and sun hours' availability parameters, alongside other programmatic and functional parameters. Grasshopper-powered Ladybug and Galapagos software were used to optimize these parameters using a generative code, with the Israeli green building code (IS 5281) providing quantitative thresholds for the analysis. In this case, the environmental iteration approach of the studio was directly implemented, with the use of an optimization algorithm to simultaneously integrate environmental considerations alongside other design parameters. As a result, the urban space which was created beneath the new parliament building allowed not only for street-level pedestrian continuity but also addressed issues of outdoor comfort. However, despite the solar driven massing, the decision to demolish the entire lower part of the existing building was not supported by a valid environmental justification, mainly due to lack of available indicators and tools to perform a thorough life cycle analysis within the project's limited scope.

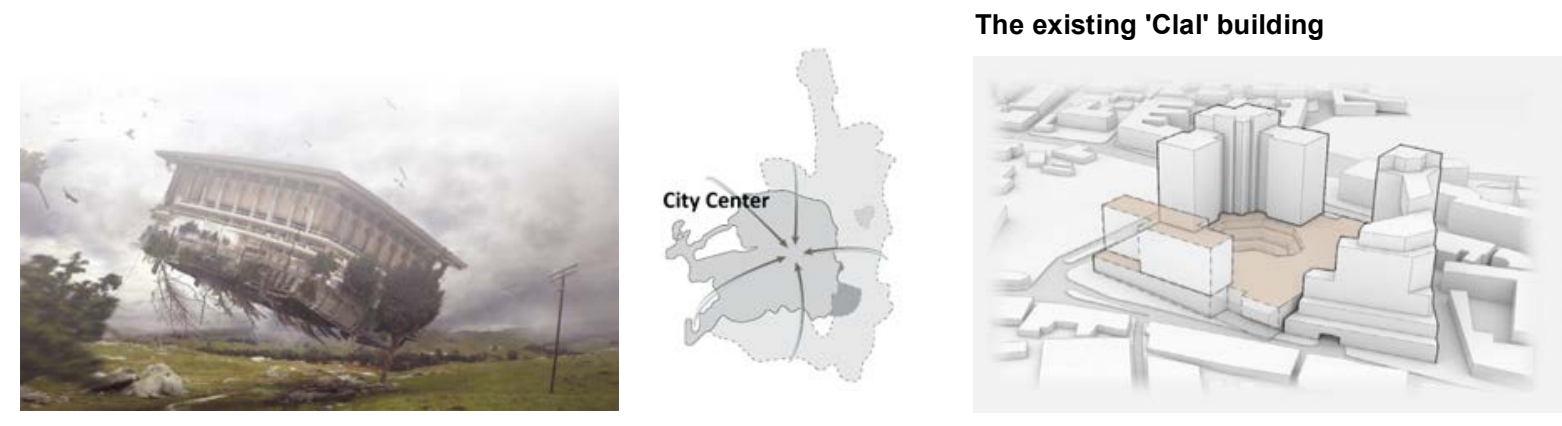

Parametric optimization process

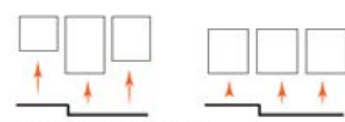

Differential floor level
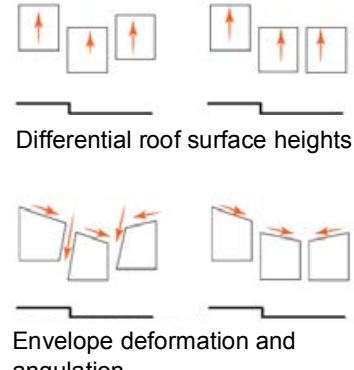
angulation

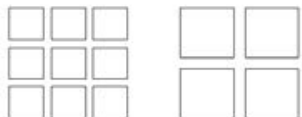

Urban block sub-division

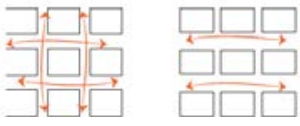

Differential distance between buildings to allow solar rights

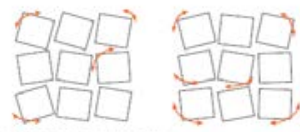

Massing orientation and physical connection

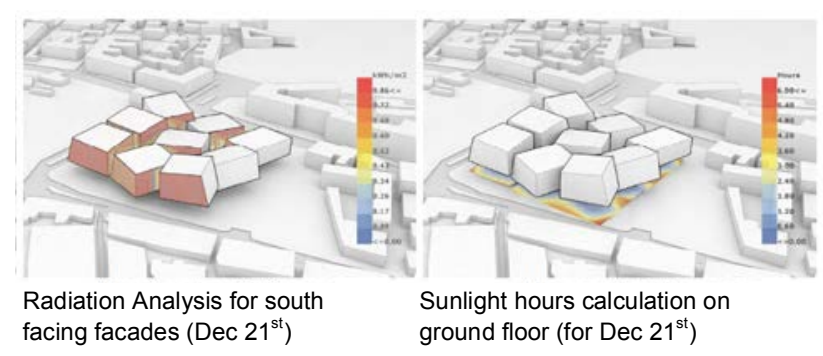

Design outcome

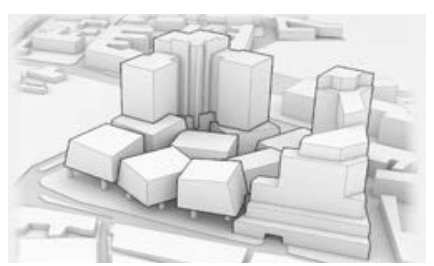

Figure 4: Redesigning the Israeli Parliament as an urban regenerator for Jerusalem's city centre by an adaptive reuse of Clal Building (project by Nattalie Mor, 2016). 


\section{Programmatic layout}

The issue of urban walkability in Tel Aviv was addressed by student Bosmat Ekstein (Figure 5). The Ayalon Highway built on the path of Ayalon River is crossing the city from north to south, creating a physical barrier between the city centre and its developing eastern areas. Ekstein's project attempted to revive the river as a public green space that connects the two parts of the city by creating a multi-purpose walkable mix of open, semi-open, and enclosed spaces.

As part of Ekstein's research work, future building plans along the Ayalon motorway were considered and modelled in 3D. The model was used in shading analyses conducted as part of the research course and in turn affected the programmatic layout of the scheme which was discussed in the design studio. The iterative process between the research module and the design studio resulted in the inclusion of varied indoor and outdoor activities and types of open spaces, positioned according to solar exposure availability on hourly and monthly cycles. In doing so, the project demonstrated how quantifiable microclimatic considerations can play an effective role in urban design without compromising other programmatic goals. Despite the limited time frame of the design studio, which did not enable to expand the microclimatic analyses, the basic shading analyses produced rich and diversified design solutions on the level of programmatic layout.

Existing and new urban pattern based on walking distances Solar availability analysis dictates programmatic concept between urban power nodes across the Ayalon Highway
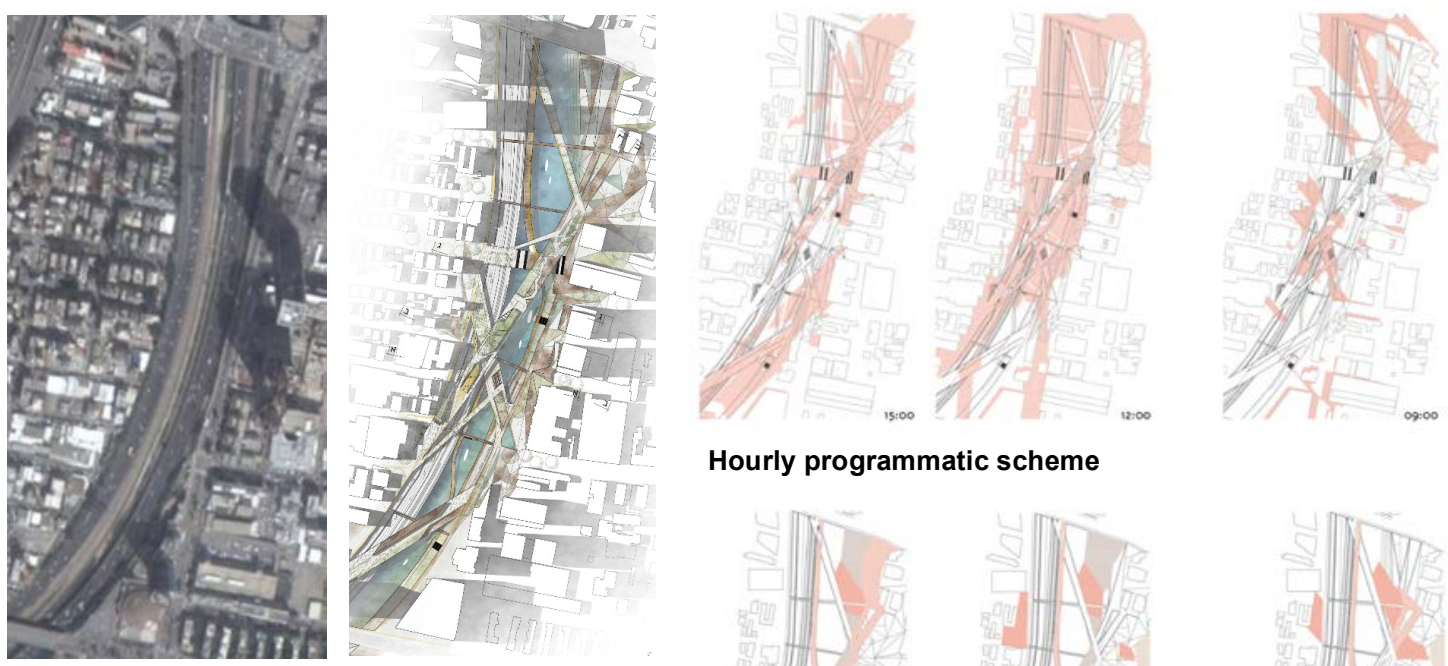

\section{Hourly programmatic scheme}
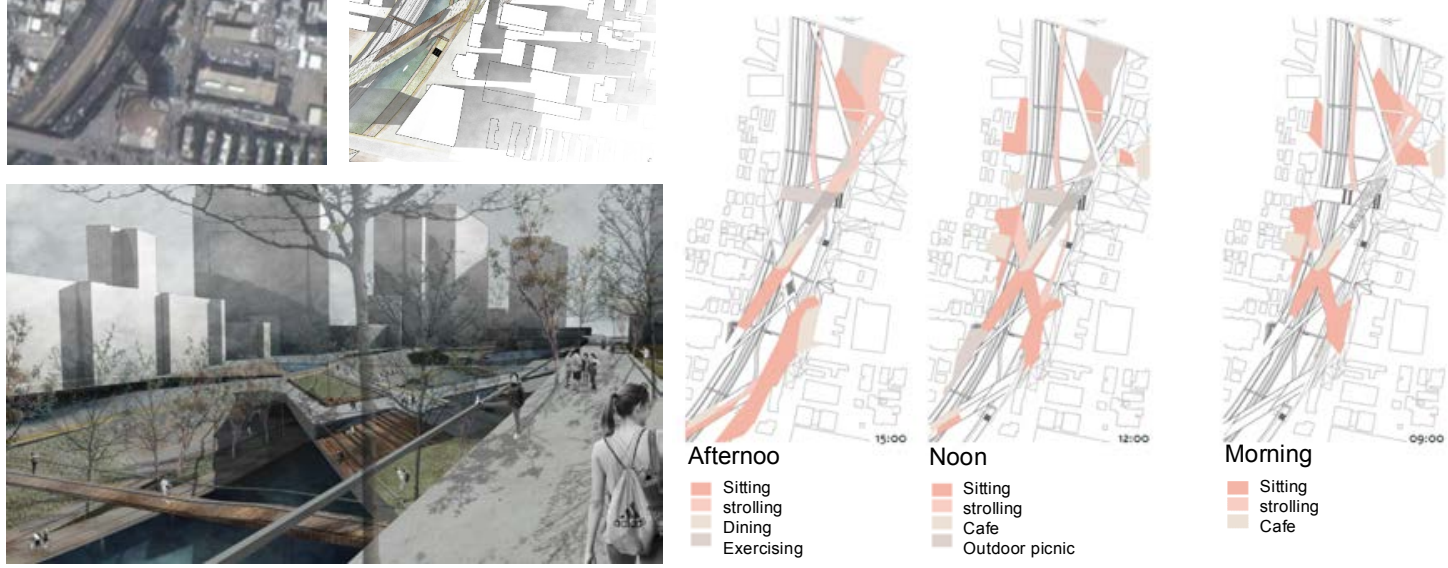

Figure 5: Transforming vehicle transportation artery into an urban walkability generator between eastern and western Tel Aviv over the Ayalon Highway (project by Bosmat Ekstein, 2016). 


\section{Envelope detailed design}

The focus of Tomer Licht's project was on one of several abandoned buildings along Haifa's waterfront (Figure 6). The project employed an adaptive reuse strategy by transforming the buildings into a collaborative working and living environment in the spirit of an existing bottom-up communal organization. The project consisted of detailed design of the housing units and communal spaces, based on the initial decision to preserve parts of the existing building. The detailed design of the complex consisted of a 3-dimensional canopy hovering above the semi-open and open communal spaces on the rooftops and central courtyard.

As part of the detailed envelope design, the canopy, which was developed during the studio sessions as the project's unifying element, integrated performative features of shading and energy production that derived from the environmental research course. Based on climatic analysis, the canopy's form and detailing were parametrically optimized by the student to admit high levels of solar radiation during winter while blocking it during summer. The project demonstrated how the outcomes of the iterative process could be manifested in the micro scale and further along the design process while still achieving an important impact on the design outcome.

Existing half-abandoned building in Haifa's deteriorating downtown area along the beach front

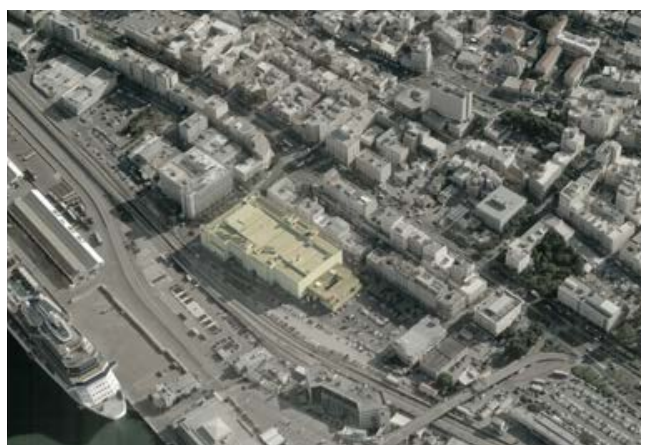

Existing building

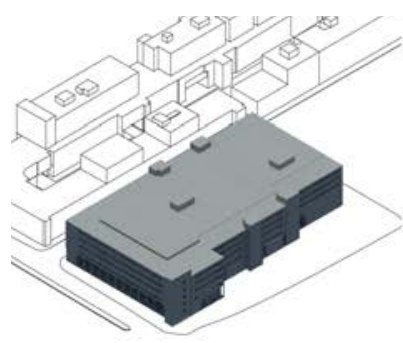

Proposed scheme

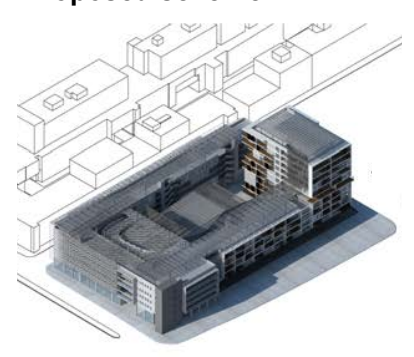

Proposed scheme combining old and new wings unified by an energy productive shading envelope
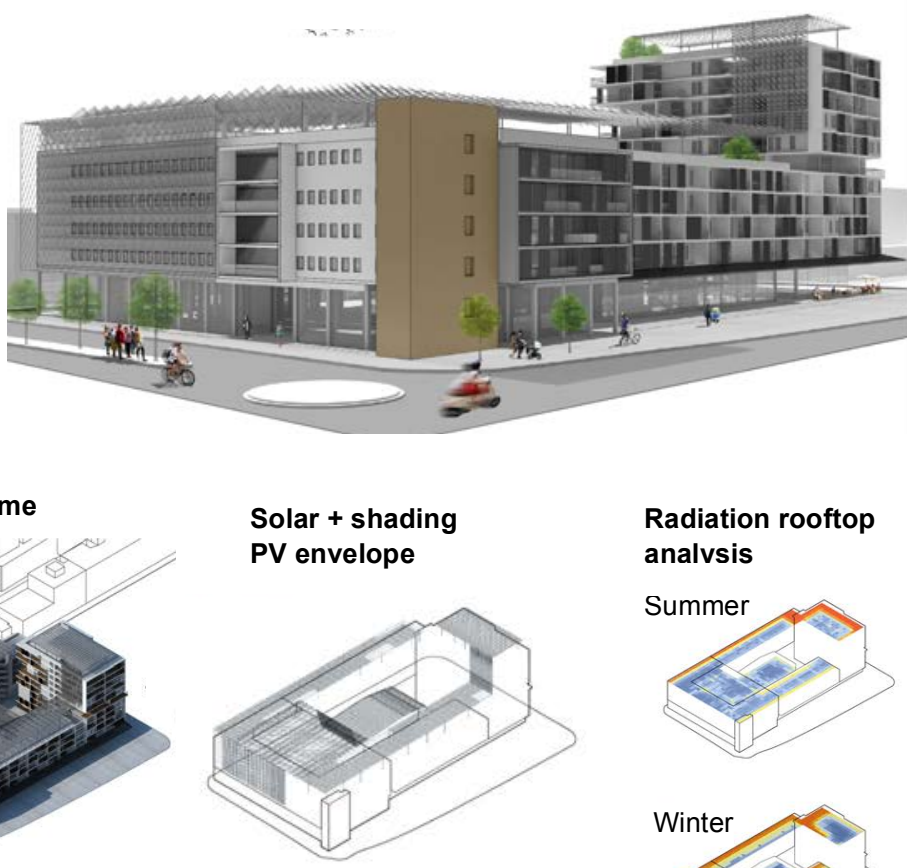

Radiation rooftop analvsis

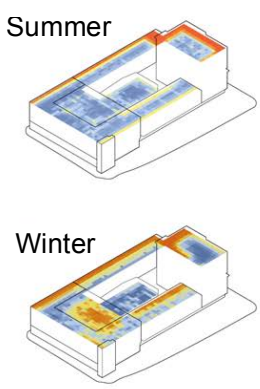

Figure 6: Adaptive reuse of an old port building into a collaborative residential complex in downtown Haifa (project by Tomer Licht, 2016). 


\section{DISCUSSION}

The four projects presented here demonstrate the challenges and opportunities of integrating an iterative environmental approach throughout different design stages within the framework of final-year architectural projects, as follows:

\section{Scope of engagement}

Although students were encouraged to apply an iterative environmental approach through the entire process of design, experience showed that they usually tended to limit their environmental focus to only specific stages of the design process. The restricted time frame, in addition to the limited theoretical and analytical background of the students, compromised the students' capability to apply a more holistic approach to environmental design. Therefore, it might be useful to encourage the implementation of environmental strategies during specific parts of the design process only, rather than to expect comprehensive engagement. This could be achieved by focusing either on certain intervention scales (for example, focusing on sustainable urbanism), or by redefining the environmental focus in accordance with the project's theme during the process of design.

\section{Quantitative indicators}

A key pedagogic issue is the quantification of environmental themes through well-defined indicators. Quantitative indicators proved to invigorate original design strategies, which in turn produced intelligent design solutions. Additionally, relying on quantitative indicators helped to set an evaluation reference point according to measurable criteria. The examples reviewed here show that while quantitative indicators may be generated from a computational analysis, they may also derive from surveys, technical reports, or literature reviews.

\section{Analytic tools}

In undergraduate final-year projects, computational tools could be extremely useful in producing quantitative indicators that could guide informed decision making along the design process. However, without prior knowledge of these tools (even on a basic level), only limited number of students would be willing or able to implement these tools in their projects. Thus, computational tools, among other analytic methods, must be taught earlier on through dedicated workshops, alongside theoretical background lectures focusing on environmental design fundamentals and indicators. With such a preliminary training, the precious tutorial time that is spent on teaching these analytic tools could be dedicated to concrete discussions on analyses results and their design implications.

\section{Thematic framework}

The four students' projects demonstrated wide variety of themes, approaches, scales, and typologies. In order to support this wide knowledge range without compromising research quality, the research module of the final-year studio must be built upon a flexible thematic framework, and to gradually generate a cumulative body of knowledge that will benefit also future students. A flexible research framework will enable to effectively adapt to new 
challenges, approaches, and tools that are rapidly changing in the field of sustainable environmental design.

\section{CONCLUSION}

This paper examined the application of the iterative approach to environmental design in a final-year design studio. Four student projects were reviewed and analysed, all conducted under the framework of a final-year design studio entitled "Articulation, space and sustainability". The projects demonstrate how an iterative dialogue between the domains of environmental research and creative design can generate a successful integration of environmental values into design. While the research module of the design studio produced quantitative indicators through the use of analytic tools and other resources, research insights supported design decisions and invigorated new and innovative concepts in the design studio.

However, as experience showed, applying an iterative framework during the later stages of architectural training has its limitations where substantial preliminary exposure of students to environmental design theories and techniques is lacking. Maybe the most significant of all is the restricted capacity of students to apply environmental knowledge throughout the entire design process, leading to its application for answering specific design questions only. In addition, it was evident that students find the use of new analytic tools a challenging task during their final-year of training, especially because the time spent on acquiring proper skills of mastering the tools prevents a proper development of the design itself. These outcomes indicate the need to consider an early integration of environmental values, theories, and tools during earlier stages of architectural education, an integration that could be elective in its nature. Looking forward, the environmental research-based design framework should be constructed on a cumulative body of knowledge that will enable to adapt to changing themes, scales, and tools that are expected to reshape the reference point for future final-year design studios.

\section{ACKNOWLEDGEMENTS}

The authors would like to thank Maayan Sheiman, Nattalie Mor, Bosmat Ekstein, and Tomer Licht for allowing us to share their work. Additional acknowledgements should go to Arch. Shmaya Serfaty, the design director of the studio "Articulation, Space, and Sustainability", and to Profs. Gaby Schwartz, Alona Nitzan-Shiftan, Guedi Capeluto, and Abraham Yezioro for their academic support.

\section{REFERENCES}

Ahmed, N. (2010). Comprehensive Environmental Design (CED) Studio in Two Architecture Schools in Karachi: Evolution, Process and Impacts. ArchNet-IJAR: International Journal of Architectural Research 4(1), 130-148. doi:10.26687/archnet-ijar.v4i1.67

Altomonte, S. (2009). Environmental Education for Sustainable Architecture. Review of European Studies, 1(2), 12. Doi:10.5539/res.v1n2p12

Altomonte, S., Cadima, P., Yannas, S., Herde, A. d., Riemer, H., Cangelli, E., Asiain, M. I., d., \& Horvath, S. (2012). Educate ! Sustainable Environmental Design in Architectural Education and Practice. In: 28th International PLEA Conference proceedings, Lima, Peru, 7 - 9 November 2012. 
Altomonte, S., Rutherford, P., \& Wilson, R. (2014). Mapping the way forward: Education for sustainability in architecture and urban design. Corporate Social Responsibility and Environmental Management, 21(3), 143-154. doi:10.1002/csr.1311

Hassanpour, B., Alpar Atun, R., \& Ghaderi, S. (2017). From Words to Action: Incorporation of Sustainability in Architectural Education. Sustainability, 9(10), 1790. doi:10.3390/su9101790

Ismail, M. A., Keumala, N., \& Dabdoob, R. M. (2017). Review on Integrating Sustainability Knowledge into Architectural Education: Practice in the UK and the USA. Journal of Cleaner Production, 140, 1542-1552. doi:10.1016/j.jclepro.2016.09.219

Al-Hagla, K. S. (2012). The Role of the Design Studio in Shaping an Architectural Education for Sustainable Development: The Case of Beirut Arab University. ArchNet-IJAR: International Journal of Architectural Research, 6(1), 23-41. doi:10.26687/archnet-ijar.v6i1.75

Kulper, A. (2013). Introduction. Journal of Architectural Education, 67(2), 254-254. doi: 10.1080/10464883.2013.817170

Reinhart, C. F., Dogan, T., Ibarra, D., \& Samuelson, H. W. (2012). Learning by Playing - Teaching Energy Simulation as a Game. Journal of Building Performance Simulation, 5(6), 359-368. doi:10.1080/19401493.2011.619668

Rob, F. (2002). Survivor Studio @ Philadelphia University: Promoting Sustainability in the Design Studio Through Collaborative Game Playing. International Journal of Sustainability in Higher Education, 3(2), 146-154. doi:10.1108/14676370210422366

Salama, A. M. (2008). A Theory for Integrating Knowledge in Architectural Design Education. ArchnetIJAR: International Journal of Architectural Research, 2(1), 100-128. ISSN:1994-6961

Susannah, D. (2013). Balance in Control: The Case of an Urban Design Studio at the University of Arizona. Archnet-IJAR: International Journal of Architectural Research, 7(1), 74-85. doi:10.26687/archnet-ijar.v7i1.126

Wright, J. (2003). Introducing Sustainability into the Architecture Curriculum in the United States. International Journal of Sustainability in Higher Education, 4(2), 100-105. doi:10.1108/14676370310467131

Yannas, S. (2013). Architectural Research for Sustainable Environmental Design. In: European Network of Heads of Schools of Architecture Conference on Environmental Design, Chania, Greece. October 2013. 